\title{
Research Paper: Effects of Combined Training on the Levels of Obestatin, Ghrelin, and Insulin Resis- tance in Overweight Women
}

\author{
Zahra Yosefi Chermahini $^{1}$, Farzaneh Taghian $^{1 *}$ (D), Mehdi Hedayati ${ }^{2}$ (D)
}

1. Department of Physical Education and Sport Sciences, Isfahan (Khorasgan) Branch, Islamic Azad University, Isfahan, Iran 2. Cellular and Molecular Endocrine Research Center, Research Institute for Endocrine Sciences,Shahid Beheshti University of Medical Sciences Tehran, Iran.

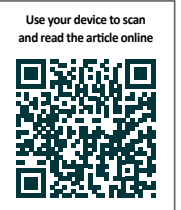

Citation Yosefi Chermahini Z, Taghian F, Hedayati M. Effects of Combined Training on the Levels of Obestatin, Ghrelin, and Insulin Resistance in Overweight Women. Journal of Research \& Health. 2020; 10(5):287-294. http://dx.doi.org/10.32598/ JRH.10.5.552.3

http://dx.doi.org/10.32598/JRH.10.5.552.3

\section{Keywords:}

Circuit-based exercise, Overweight, Ghrelin, Obestatin, Insulin resistance

\section{A B STRACT}

Background: The present quasi-experimental and field research was conducted to evaluate the effect of combined exercises on the levels of obestatin and ghrelin in overweight women.

Methods: The study subjects consisted of 34 overweight women with a Mean \pm SD age of $30.29 \pm 4.66$ years, a Mean \pm SD height of $165.11 \pm 5.56 \mathrm{~cm}$, a Mean \pm SD weight of $74.64 \pm 7.33$ $\mathrm{kg}$, a Mean \pm SD body mass index of $27.35 \pm 1.74 \mathrm{~kg} / \mathrm{m}^{2}$, which were selected purposefully and randomly, and assigned to the experimental $(n=17)$ and control $(n=17)$ groups. At first, venous blood samples were taken from subjects after $12 \mathrm{~h}$ overnight fasting to measure the levels of ghrelin, obestatin, glucose, insulin, and insulin resistance. Then, the participants of the experimental group participated in a combined exercise program, including warming up, aerobic training, resistance training, and cooling down. All these variables were re-measured after 12 weeks and the obtained data were analyzed. The paired $t$ test was used for intra-group comparison and independent $t$ test was performed for inter-group comparison.

Results: The findings of this study showed that body weight, BMI, waist circumference, glucose level, and ghrelin-obestatin ratio were significantly different between the experimental and the control groups $(\mathrm{P} \leq 0.05)$ after 8 weeks of combined exercise training, but differences in ghrelin, obestatin, insulin levels, and insulin resistance were not significant between the experimental and control groups $(\mathrm{P} \leq 0.05)$.

Conclusion: The combined exercise training, therefore, seems to be a suitable method for weight loss, body composition, waist circumference, glucose level, and ghrelin-obestatin ratio.

\footnotetext{
* Corresponding Author:

Farzaneh Taghian, PhD.

Address: Department of Physical Education and Sport Sciences, Isfahan (Khorasgan) Branch, Islamic Azad University, Isfahan, Iran.

Phone: +98 (31) 15353135

E-mail:ftaghian@yahoo.com
} 


\section{Introduction}

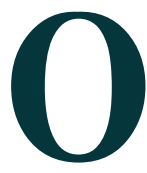

besity is one of the significant health problems around the world. Because of urbanization, industrialization, increased economic growth, and globalization of the market, the patterns of diet and lifestyle of the people have encounters rapid changes [1].

Adjusted body weight is a highly complex and accurately controlled process in which peptides in the stomach and brain play an important role [2]. The connections between the gastrointestinal tract and the Central Nervous System (CNS) are important parts of regulating appetite. The Gut-Brain Axis (GBA) has neural and hormonal portions that transmit data to important neurological centers, including the hypothalamus and brain stem [3].

The connective pathways between the digestive system and the CNS are important parts of regulating appetite. Combined exercise activity is likely to increase the level of growth hormone, which acts as an obestatin secretion inhibitor. The growth hormone is controlled through negative feedback by inhibiting fundus obestatin concentration [3].

Both ghrelin and obestatin are derived from preproghrelin with different post-translational changes. The obestatin receptor (GPR) is expressed in gastric, intestinal, pancreatic, pituitary, hypothalamic, and lipid tissues. The obestatin is involved in the metabolism of energy, glucose, and fat; the regulation of body weight; and the secretion of insulin. Besides, it is an appetite suppressant and causes decreased gastric emptying and intestinal contractions. This peptide is also associated with obesity and diabetes. The findings have shown that ghrelin is sensitive to negative energy conditions and plays a significant role in the short-term and long-term energy balance as well as glucose homeostasis [4].

The ghrelin is a 28-amino acid peptide, released from the gastrointestinal cells, known as an appetite stimulant, expressed from gastric, intestinal, pancreatic, kidney, hypothalamic, and pituitary cells. It is located in the cell membrane of ghrelin cells in the stomach and pancreas. Research findings show that the expression of the ghrelin gene in the stomach increases during fasting and decreases in satiety. The plasma level of ghrelin decreases under positive energy balance conditions and increases in negative energy balance conditions [2]. Several factors can affect appetite levels, including sports activities.
There is evidence regarding the effects of physical activity and exercise on energy resources, appetite, energy intake, and energy expenditure. Muscle glycogen depletion is caused by the energy demand of muscles and the consequent reduction of liver glycogen to maintain blood glucose and energy intake and is one of the routine effects of the activity. Exercise, as a human body constrictor, can develop a negative energy balance, followed by activating the mechanisms involved in regulating and balancing energy [5]. Previous studies have shown the effects of physical activity, especially severe and prolonged activity, on the significant depletion of ATP, liver, and muscle glycogen.

The role of ghrelin, agouti-related peptide (AGRP), and NPY as well as the effect of physical activity on energy balance and food intake have been substantiated, but the function and importance of obestatin are still ambiguous as an anti-appetite peptide contributing to energy balance to prevent weight gain. The level of obestatin may be affected by exercise and can lead to changes in appetite and weight [6].

The ghrelin-obestatin ratio plays an important role in energy balance and weight control. These peptides have opposing effects on food intake, weight gain, and adiposity. The increasing ghrelin-obestatin ratio is likely to contribute to the etiology or pathophysiology of obesity and overweight [7].

Some studies have shown that exercise-caused weight loss, followed by a decrease in BMI, can change the plasma ghrelin level $[5,6]$. Karen et al. observed that the plasma ghrelin levels increased in response to a one-year training program. This exercise program led to weight loss, without lowering the calorie intake. However, researchers suggested the hypothesis that the ghrelin participates in regulating a negative feedback loop, which is the regulator of body weight. In other words, reducing body weight leads to increased blood ghrelin levels, known to be part of adaptation to energy shortages [7].

Jafari Chashmi et al. investigated the combined effect of ghrelin levels in men. Their results indicated that the ghrelin levels increased only in combined exercise training at the upper extremity [6]. In a study by GhanbariNiaki et al., the results indicated that 6-week endurance training reduced the level of ghrelin in plasma and muscle in rats. At the end of the exercise program, there was no significant difference between the experimental and the control groups regarding the plasma levels of glucose and insulin and the weight [8]. 
Parvizi et al. investigated the effect of 12 weeks of aerobic exercise running on a treadmill on the ghrelin levels in Wistar rats and showed a significant decrease in serum acylated ghrelin and no effect on the stomach tissue acylated ghrelin [9]. In general, although resistance activities are a very important part of an exercise for weight loss, the effect of these exercises on ghrelin peptide, which plays an important role in energy metabolism, has not been studied. Besides, some scientific sources also state that changes in the ghrelin levels are effective in insulin resistance [10].

About hormonal and metabolic studies, still many questions exist about changes in the ghrelin levels as one of the factors affecting energy balance due to training exercises. Also, the effect of weight loss due to training exercises on the plasma ghrelin level requires further investigation. Given that most people use the combined program, including resistance and endurance training, in the process of preparation, and since nature and adaptations resulting from resistance and aerobic exercises are different and opposite in some cases, the purpose of this research was to determine the effect of combined exercise training on the levels of ghrelin, obestatin, and insulin resistance in overweight women.

\section{Methods}

The present quasi-experimental and field research was conducted with an experimental group and a control group in 2017 in Isfahan City, Iran. The study population was all overweight women living in Isfahan. To complete the sample size, a poster was installed at several municipal cultural centers and gyms to invite overweight women to participate in the study. Subsequently, eligible individuals were selected based on the inclusion criteria. The inclusion criteria were the age range of 25 to 45 years; the Body Mass Index (BMI) between 25 and 30 ; no history of cardiovascular, respiratory, liver, kidney, brain, and hormonal disease; lack of a weight loss program in a recent year; the absence of hypertension and lack of regular physical activities in the last year.
The subjects were asked to complete a physical activity readiness questionnaire. Finally, 34 eligible candidates were selected to participate in the study by purposeful and convenient sampling method, and randomly assigned to two groups of control $(\mathrm{n}=17)$ and experimental $(n=17)$. The sample size was determined based on previous articles. The exclusion criterion was the lack of regular engagement in research. In this research, no dropout was observed according to the researcher's follow-up. During a meeting, the volunteers were briefed on the type of study, its objectives, procedure, benefits, and risks, and then signed informed consent.

The samples' height, weight, and BMI were measured with a minimal dress and no shoes. The weight of subjects was measured via a scale with an accuracy of 0.1 $\mathrm{kg}$ (made in Germany) and their height was measured by tape measure with an accuracy of $0.5 \mathrm{~cm}$. The BMI was calculated by dividing body weight in kilograms (kg) by height in square meter $\left(\mathrm{m}^{2}\right)$.

Before the beginning of the training program, the subjects participated in a series of briefing sessions on exercises, safety-training principles, and the systematic use of gym equipment. Then, the values of one repetition maximum were determined. The pressure and the frequency of repetition of each exercise were determined individually based on their abilities and physical fitness. The experimental group performed combined exercise training for 8 weeks and three times a week. Each session consisted of 5 minutes of warm-up, 45 minutes of resistance training, 30 minutes of aerobic training (running) and finally cooling down.

The control group during the study period went to normal daily activities. Eight resistance exercises included upper, lower, and core muscle groups such as leg press, leg flexion, leg extension, chest press, armpit muscle movement, bicep exercises, and shoulder workout. The aerobic exercise included running in the gym. The duration and intensity of aerobic exercise are presented in Table 1. The duration of the exercise at the start of the

Table 1. The combined exercise training program

\begin{tabular}{|c|c|c|c|c|c|c|c|c|}
\hline & & $1^{\text {st }} \& 2^{\text {nd }}$ Weeks & $3^{\text {rd }}$ Week & $4^{\text {th }}$ Week & $5^{\text {th }}$ Week & $6^{\text {th }}$ Week & $7^{\text {th }}$ Week & $8^{\text {th }}$ Week \\
\hline Aerobic & Duration (min) & 10 & 15 & 20 & 20 & 25 & 30 & 30 \\
\hline \multicolumn{2}{|c|}{ Intensity (maximum heart rate) } & \multicolumn{3}{|c|}{$60 \%-65 \%$} & \multicolumn{4}{|c|}{$65 \%-70 \%$} \\
\hline Resistance & & \multicolumn{3}{|c|}{$50 \%-55 \%$ of one repetition maximum } & \multicolumn{4}{|c|}{$55 \%-60 \%$ of one repetition maximum } \\
\hline
\end{tabular}


study was 10 minutes, which increase to 30 minutes in the eighth week [10].

To keep the caloric intake constant during the study, the dietary intake was recorded via the $24 \mathrm{~h}$ dietary recall (24 h) in three days (Saturday, Sunday, Friday) in the first, sixth, and final weeks.

To measure the biochemical variables, the blood samples were taken from subjects after 12 hours of fasting and in 2 steps before the intervention and then 12 weeks after the intervention. Five milliliters of venous blood samples taken from the subjects were centrifuged at $3000 \mathrm{rpm}$, and serum was collected and stored at $-80^{\circ}$ C. The enzymatic colorimetric method (sensitivity of 5 $\mathrm{mL} / \mathrm{dL}$ ) was used to measure serum fasting glucose. The serum insulin concentration was measured by ELISA assay and using a special kit (Monobind Inc, USA). The insulin resistance index was calculated using the HOMA-IR equation [11].

HOMA-IR: fasting insulin $(\mathrm{U} / \mathrm{mL}) \times$ fasting glucose $(\mathrm{mmol} / \mathrm{L}) / 22.5$

The plasma ghrelin level was measured using the EASTBIOPHRM kit with the code of Ghrelin (GH) Elisa Kit human code - CK Cat. No E10638 with a sensitivity of $0.01 \mathrm{ng} / \mathrm{mL}$ (China under license of the US). The plasma obestatin level was measured using the EASTBIOPHRM kit with Human Obestatin (OB) Elisa Kit Cat.No code: CK-E90108 with a sensitivity of $0.01 \mathrm{ng} / \mathrm{mL}$ (China under license of the US). After 8 weeks of intervention, all variables measured in the Pre-test were re-measured. Descriptive statistics were used to examine the subjects' characteristics, including age, height, weight, BMI, glucose level and fasting insulin, insulin resistance index, ghrelin, obestatin, and ghrelin-obestatin ratio in two groups. After examining the normal distribution of data with the help of the Kolmogorov-Smirnov test, the paired $t$ test was used for the intra-group analysis and the independent $t$ test for the inter-group comparison in the SPSS V. 22. The significance level for calculations was considered (0.05).

\section{Results}

The current study was performed on 34 overweight women. Table 2 presents the measures of central tendency related to the general characteristics of subjects in the Pre-test, including age, weight, waist circumference, and $\mathrm{BMI}$ in the experimental and control groups.

As shown in Table 3, only ghrelin-obestatin ratio, glucose level, weight, BMI, and waist circumference are significant in the experimental group $(\mathrm{P}=0.05)$. In Table 3 , the inter-group comparisons are evaluated for study variables.

As seen in Table 4, the differences in ghrelin-obestatin ratio, weight, BMI, and waist circumference are significant between the experimental and control groups $(\mathrm{P}<0.05)$. The results of Table 4 show the normal distribution of data.

\section{Discussion}

As shown in Table 5, the data distribution was normal using the Kolmogorov-Smirnov test. The results showed that 8 weeks of combined exercise training did not affect ghrelin concentration in overweight women. Although ghrelin levels increased slightly in the experimental group after 8 weeks of training, this change was not significant. In the present study, no significant changes were observed in ghrelin levels after 8 weeks of combined exercise.

The mechanism of the relationship between ghrelin and physical activity has been evaluated, which is likely to result in a negative energy balance in the body and ghrelin released in response to energy shortages to stimulate food intake behavior, the supply of lost energy, and establish energy balance [2]. The results showed that 8 weeks of combined exercise training did not affect ghrelin concentration in overweight women. Although ghrelin levels in-

Table 2. Comparison of mean age and BMI between the two study groups before the intervention

\begin{tabular}{|c|c|c|c|c|}
\hline Group Variable & Combined Exercise Training & Control & $\mathbf{t}$ & Sig. \\
\hline Age (y) & $30.29 \pm 4.66$ & $31.40 \pm 3.56$ & 1.39 & 0.26 \\
\hline Weight (kg) & $74.64 \pm 7.33$ & $73.06 \pm 4.09$ & 4.2 & 0.36 \\
\hline $\mathrm{BMI}\left(\mathrm{kg} / \mathrm{m}^{2}\right)$ & $27.35 \pm 1.74$ & $27.01 \pm 1.40$ & 1.17 & 0.33 \\
\hline Waist circumference $(\mathrm{cm})$ & $97.17 \pm 7.44$ & $92.73 \pm 7.89$ & 3.17 & 0.57 \\
\hline
\end{tabular}


Table 3. Intra-group comparison of plasma ghrelin, obestatin, and ghrelin-obestatin ratio before and after training in the experimental and control groups

\begin{tabular}{|c|c|c|c|c|}
\hline Variables & Group & Mean Difference & $\mathbf{t}$ & $\mathbf{P}$ \\
\hline \multirow{2}{*}{ Ghrelin (ng/mL) } & Experimental & $-0.23 \pm 0.66$ & -1.44 & 0.16 \\
\hline & Control & $0.01 \pm 0.25$ & -0.18 & 0.85 \\
\hline \multirow{2}{*}{ Obestatin (ng/mL) } & Experimental & $0.35 \pm 0.86$ & 1.70 & 0.10 \\
\hline & Control & $0.04 \pm 0.25$ & -0.69 & 0.49 \\
\hline \multirow{2}{*}{ Ghrelin- obestatin ratio } & Experimental & $0.21 \pm 0.29$ & -2.99 & 0.009 \\
\hline & Control & $0.0008 \pm 0.18$ & 0.01 & 0.98 \\
\hline \multirow{2}{*}{ Glucose level (mg/dL) } & Experimental & $12.29 \pm 11.04$ & 4.58 & 0.001 \\
\hline & Control & $0.13 \pm 7.17$ & 0.07 & 0.94 \\
\hline \multirow{2}{*}{ Insulin (mIU/L) } & Experimental & $-7.69 \pm 21.89$ & -1.44 & 0.16 \\
\hline & Control & $-1.09 \pm 2.86$ & -1.47 & 0.16 \\
\hline \multirow{2}{*}{ Insulin resistance } & Experimental & $-1.46 \pm 5.66$ & -1.06 & 0.30 \\
\hline & Control & $-0.21 \pm 0.64$ & -1.30 & 0.21 \\
\hline \multirow{2}{*}{ Weight (kg) } & Experimental & $2.32 \pm 0.84$ & 10.84 & 0.001 \\
\hline & Control & $0.16 \pm 0.91$ & 0.70 & 0.49 \\
\hline \multirow{2}{*}{$\mathrm{BMI}\left(\mathrm{kg} / \mathrm{m}^{2}\right)$} & Experimental & $0.92 \pm 0.54$ & 6.95 & 0.001 \\
\hline & Control & $0.07 \pm 0.32$ & 0.86 & 0.40 \\
\hline \multirow{2}{*}{ Waist circumference $(\mathrm{cm})$} & Experimental & $2.02 \pm 0.72$ & 11.55 & 0.001 \\
\hline & Control & $0.10 \pm 1.28$ & 0.30 & 0.76 \\
\hline
\end{tabular}

IPA:

creased slightly in the experimental group after 8 weeks of training, this change was not significant. In the present study, no significant changes were observed in ghrelin levels after 8 weeks of combined exercise.
Although the increase in ghrelin was not significant in this study, a slight increase in ghrelin levels is thought to be due to exercise, and the levels of ghrelin are also thought to increase further with continued exercise or increased exercise intensity. Although Zakavi et al. (2015)

Table 4. Inter-group comparison of plasma ghrelin, obestatin, and the ghrelin-obestatin ratio between the two groups

\begin{tabular}{cccc}
\hline Variables & Mean Difference & $\mathbf{t}$ & $\mathbf{P}$ \\
\hline Ghrelin $(\mathrm{ng} / \mathrm{mL})$ & 0.21 & 1.20 & 0.23 \\
\hline Obestatin $(\mathrm{ng} / \mathrm{mL})$ & -0.40 & -1.73 & 0.09 \\
\hline Ghrelin- obestatin ratio & 0.21 & 2.43 & 0.02 \\
\hline Glucose level $(\mathrm{mg} / \mathrm{dL})$ & -12.16 & -3.63 & 0.001 \\
\hline Insulin $(\mathrm{mlU} / \mathrm{L})$ & -6.60 & 1.15 & 0.25 \\
\hline Insulin resistance & 1.24 & 0.84 & 0.38 \\
Weight $(\mathrm{kg})$ & -2.06 & -6.61 & 0.001 \\
\hline BMI $\left(\mathrm{kg} / \mathrm{m}^{2}\right)$ & -0.85 & -5.28 & 0.001 \\
\hline Waist circumference $(\mathrm{cm})$ & -1.92 & -5.31 & 0.001 \\
\hline
\end{tabular}


Table 5. The Kolmogorov-Smirnov test to verify normal data distribution

\begin{tabular}{|c|c|c|c|c|}
\hline \multirow{3}{*}{ Statistical Index } & \multicolumn{4}{|c|}{$\mathbf{P}$} \\
\hline & \multicolumn{2}{|c|}{ Experiment } & \multicolumn{2}{|c|}{ Control } \\
\hline & Pre-test & Post-test & Pre-test & Post-test \\
\hline Weight (kg) & 0.96 & 0.99 & 0.22 & 0.56 \\
\hline $\mathrm{BMI}\left(\mathrm{kg} / \mathrm{m}^{2}\right)$ & 0.74 & 0.85 & 0.99 & 0.78 \\
\hline Waist circumference $(\mathrm{cm})$ & 0.87 & 0.77 & 0.18 & 0.29 \\
\hline Glucose level (mg/dL) & 0.58 & 0.60 & 0.61 & 0.52 \\
\hline Insulin (mIU/L) & 0.35 & 0.37 & 0.68 & 0.95 \\
\hline Insulin resistance & 0.35 & 0.25 & 0.89 & 0.88 \\
\hline Ghrelin (ng/ml) & 0.12 & 0.10 & 0.80 & 0.17 \\
\hline Obestatin (ng/ml) & 0.48 & 0.08 & 0.48 & 0.81 \\
\hline Ghrelin-obestatin ratio & 0.27 & 0.94 & 0.93 & 0.49 \\
\hline
\end{tabular}

showed that the ghrelin level significantly decreased in the elderly after Pilates training [12], Khalilzadeh et al. (2011) found that the effect of 8 weeks of mild and moderate aerobic activity on plasma acylated ghrelin in inactive women was not significant, but a slight increase was observed [13]. Irandoust et al. (2009) argued that the high variability of ghrelin is likely to be one of the important factors in not increasing ghrelin [14]. On the other hand, they reported that the metabolic effects induced by exercise were likely to be effective on changes in the levels of non-acylated ghrelin independently of weight loss.

In support of this finding, Foster-Schubert et al. (2005) stated that even 1 year exercise, independent of changes in body weight, did not affect the plasma ghrelin concentration, while the plasma ghrelin levels also increased in people whose body weight reduced by exercise [15]. Tofighi et al. (2014) examined the effect of 8-week aerobic endurance training on changes in Nesfatin-1 and acylated ghrelin in young obese males [16] and showed that the exercise does not affect ghrelin variations, which is in line with the results of this study.

The increase in ghrelin is probably associated with weight loss and body composition indexes. Besides, the ghrelin increases with serum triglyceride concentrations, and the ghrelin levels have a direct correlation with fat percentage. The combined exercise training led to increased ghrelin in the present study, possibly with fat percentage and weight loss. Although the increase of ghrelin was not significant in this study, the results showed no significant difference in the Pre-test and Post- test levels of obestatin between the experimental and control groups. The results of the present study are inconsistent with the results of the research conducted by Yaryan and Ebrahimi but consistent with the results of Taghian and Zolfaghari $[3,17,18]$.

Hoseyni et al. studied the acute effects of circuit resistance training and Ebrahimi examined aerobic exercises on the obestatin level. Both studies employed young subjects, and the level of obestatin decreased. In the present study, no significant change occurred in the plasma obestatin level probably due to the low duration and intensity of exercise and the type of combined exercise training (resistance-aerobic). In general, the type and intensity of training programs and the age of the subjects seem to be effective in how responses and adoptions are made. Also, the fasting and absence of subjects during the research, their weight and BMI, the type of exercise program used, and even post-activity sampling time may play a role in the inconsistency of the findings. Taghian et al. showed that 12 weeks of aerobic training did not make a significant difference in the obestatin level between obese women, which is consistent with this study finding [3]. The intensity and the duration of exercise in the research of Taghian et al. probably were not similar to the current study.

The results of this study showed that 8 weeks of combined exercise training affected the weight and BMI of overweight women and caused a significant decrease in these variables. In line with this research, Zakavi et al. reported a significant impact of Pilates training on BMI and weight loss [12]. Abdi Keikanlo et al. also showed 
that 8 weeks of aerobic training significantly decreased the weight and BMI of obese women [19]. Weight loss and BMI changes can be explained by weight loss and increased muscle mass.

Research by Irandoust et al. (2010) is also consistent with ours [14]. Hence, it can be argued that regular and long-term sports activities, by increasing energy costs and subsequently creating a negative energy balance, can help maintain or reduce weight [20]. Regarding the results of changes in ghrelin and obestatin, it seems that a decrease in body mass and lean body mass is likely to be necessary to change the levels of these variables, which also depends on the exercise intensity because the changes in ghrelin and obestatin will be elevated with increasing exercise intensity. However, the combined exercise training in accordance with the training protocol of this study is of considerable benefit to overweight women, and if the training continues, there will be beneficial outcomes resulting in the health promotion of these individuals. One of the study limitations is the lack of proper diet control.

\section{Conclusion}

The findings of the study indicated the significant role of combined exercise training on weight, BMI, waist circumference, and ghrelin-obestatin ratio in overweight women. Although the increase in ghrelin levels and the reduction of obestatin was not significant, the importance of changes in this variable cannot be overlooked. Multiple studies are suggested with different subjects and various types of exercises to examine the indexes associated with obesity and appetite, which were inconsistent with this study. It seems that the intensity, the duration, and the history of the exercise of the subjects have an important role in the effect of combined exercise training on ghrelin and obestatin levels. The benefits of implementing 8 weeks of combined exercise training to promote the health of overweight women through their effects on appetite hormones, weight loss, and body composition make it possible to perform this kind of exercise with certainty.

\section{Ethical Considerations}

\section{Compliance with ethical guidelines}

Ethical approval for this article has been registered with license No 98-04-14-2-8511.

\section{Funding}

The present paper was extracted from the MSc. thesis of the first author in sports physiology approved by the Department of Physical Education and Sport Science , Isfahan Branck (Khorasgan), Islamic Azad University.

\section{Authors' contributions}

Study design: Zahra Yosefi Chermahini; Data collection, data analysis: Zahra Yosefi Chermahini, Farzaneh Taghian; Manuscript preparation, Approval of the final version: All authors.

\section{Conflict of interest}

The authors declared no conflict of interest.

\section{Reference}

[1] Lemamsha H, Papadopoulos C, Randhawa G. Perceived environmental factors associated with obesity in Libyan men and women. Int J Environ Res Public Health. 2018; 15(2):301. [DOI:10.3390/ijerph15020301] [PMID] [PMCID]

[2] Lean MEJ, Malkova D. Altered gut and adipose tissue hormones in overweight and obese individuals: Cause or consequence? Int J Obes. 2016; 40(4):622-32. [DOI:10.1038/ ijo.2015.220] [PMID] [PMCID]

[3] Taghian f, Zolfaghari M. Effect of 12-week aerobic exercise on the obestatin level in obese women. Journal of Jahrom University of Medical Sciences. 2013; 11(4):1-8. [DOI:10.29252/ jmj.11.4.1]

[4] Ghanbari-Niaki A, Soltani R, Shemshaki A, Kraemer RR Effects of acute ethionine injection on plasma ghrelin and obestatin levels in trained male rats. Metabolism. 2010 59(7):982-7. [DOI:10.1016/j.metabol.2009.10.020] [PMID]

[5] Klok MD, Jakobsdottir S, Drent ML. The role of leptin and ghrelin in the regulation of food intake and body weight in humans: A review. Obes Rev. 2007; 8(1):21-34. [DOI:10.1111/ j.1467-789X.2006.00270.x] [PMID]

[6] Jafari Chashmi A, Peeri M, Azarbayjani MA, Matin Homaee $\mathrm{H}$. [Effect of different resistance training modes on appetite and serum orexin, ghrelin, and neuropeptide $Y$ levels in sedentary healthy males (Persian)]. Med J Mashhad Univ Med Sci. 2018; 60(6):804-15. [DOI:10.22038/MJMS.2018.10787]

[7] Cowan E, Burch KJ, Green BD, Grieve DJ. Obestatin as a key regulator of metabolism and cardiovascular function with emerging therapeutic potential for diabetes. Br J Pharmacol. 2016; 173(14):2165-81. [DOI:10.1111/bph.13502] [PMID] [PMCID]

[8] Ghanbari-Niaki A, Abednazari H, Tayebi SM, HossainiKakhak A, Kraemer RR. Treadmill training enhances rat agouti-related protein in plasma and reduces ghrelin levels in plasma and soleus muscle. Metabolism. 2009; 58(12):1747-52 [DOI:10.1016/j.metabol.2009.06.002] [PMID]

[9] Parvizi A, Ghasemnian A, Rahmani A. [Effect of 12 weeks aerobic exercise for along with folic acid supplementation on the levels of the ghrelin hormone, amount of food intake and 
weight changes of female Wistar rats (Persian)]. Armaghane-Danesh. 2016; 21(8):746-56. http://armaghanj.yums.ac.ir/ article-1-1474-en.html

[10] Zarei M, Hamedinia M, Haghighi A, Noorafshar R, Amini S. [Effect of three combined aerobic-resistance exercise training protocols with different intensities on metabolic control and Visfatin levels in men with type 2 diabetes (Persian)]. Iran J Diabetes Metab. 2016; 16(1):63-76. http://ijdld.tums.ac.ir/ article-1-5492-en.html

[11] Kraemer RR, Durand RJ, Acevedo EO, Johnson LG, Kraemer GR, Hebert EP, et al. Rigorous running increases growth hormone and insulin-like growth factor-I without altering ghrelin. Exp Biol Med. 2004; 229(3):240-6. [DOI:10.1177/15353 7020422900304] [PMID]

[12] Zakavi I, Zakavi E, Taghian F. [Effect of Pilates training on plasma levels of ghrelin and obestatin in obese older men (Persian)]. J Shahid Sadoughi Univ Med Sci. 2015; 23(3):202131. http://jssu.ssu.ac.ir/article-1-2914-en.html

[13] Khalilzadeh M, Azali Alamdari K, Choobineh S, Ebadi Shirmard B, Ghahramani M. [Effects of aerobic training with low and intermediate intensity on appetite, body weight, exercise energy expenditure and plasma ghrelin level in relatively thin and obese sedentary women (Persian)]. Iran J Nutr Sci Food Technol. 2011; 6(1):1-10. http://nsft.sbmu.ac.ir/ article-1-463-en.html

[14] Irandoust Kh, Rahmaninia F, Mohebi H, Mirzaei B, Hasannia S. [Effects of Aerobic training on plasma ghrelin and leptin in obese and normal weight women (Persian)] Olympic. 2010; 18(2):87-99. https://www.sid.ir/fa/journal/ ViewPaper.aspx?ID=103224

[15] Foster-Schubert KE, McTiernan A, Scott Frayo R, Schwartz RS, Rajan KB, Yasui Y, et al. [Human plasma ghrelin levels increase during a one-year exercise program (Persian)]. J Clin Endocrinol Metab. 2005; 90(2):820-5. [DOI:10.1210/jc.2004-2081] [PMID]

[16] Tofighi A, Mehrabani J, Khadivi SM. [The effect of 8 weeks aerobic exercise on Nesfatin-1 and acylated ghrelin in young obese men (Persian)]. Med J Mashhad Univ Med Sci. 2014; 57(3):562-70. http:// mjms.mums.ac.ir/article_3012.html

[17] Hoseini R, Ghasemi F, Sayyah A, Rahmani Ghobadi M. [The effects of circuit resistance training on plasma levels of peptide YY and ghrelin in male athletes (Persian)]. Tabari Biomed Stud Res J. 2015; 1(1):1-9. http:/ / tbsri.mazums.ac.ir/ article-1-3442-en.html

[18] Ebrahimi M, Rahmani-Nia F, Damirchi A, Mirzaie B, Asghar Pur S. Effect of short-term exercise on appetite, energy intake and energy-regulating hormones. Iran J Basic Med Sci. 2013; 16(7):829-34. [PMID] [PMCID]

[19] Abdi Keykanlo N, Rohani H, Asari F. [Effects of 8 weeks aerobic training on body composition and plasma levels of insulinlike growth factor-1 and insulin-like growth factor binding protein-3 in obese women (Persian)]. Koomesh. 2014; 15(3):302-9. http:/ / koomeshjournal.semums.ac.ir/article-1-2055-en.html

[20] Stensel D. Exercise, appetite and appetite-regulating hormones: Implications for food intake and weight control. Ann Nutr Metab. 2010; 57(Suppl 2):36-42. [DOI:10.1159/000322702] [PMID] 